\title{
Çerçeve Türü Betonarme Binaların Periyod Hesaplarının Farklı Ampirik Bağıntılara Göre İrdelenmesi
}

\author{
Ceyhun AKSOYLU, Musa Hakan ARSLAN* \\ Konya Teknik Üniversitesi Mühendislik ve Doğa Bilimleri Fakültesi, Inşaat Mühendisliği Bölümü, Konya \\ (ORCID: 0000-0002-1574-4251) (ORCID: 0000-0002-5410-9218)
}

\begin{abstract}
$\ddot{\mathbf{O} z}$
Deprem etkisi altında bir yapının göstereceği davranış genel olarak yapının kütlesi ve yatay rijitliğine bağlıdır. Yapının dinamik karakterinin elbette sadece iki parametreye bağlı olmayacağı açıktır. Fakat diğer etmenlerle beraber periyod hesabın zorlaşması nedeniyle literatürde yaklaşık yöntemler verilmiştir. Bunlardan en çok kabul göreni ise Rayleigh'in önermiş olduğu birinci doğal titreşim periyodu denklemidir. Bu çalışmada 1998, 2007 ve 2018 Türk Deprem Yönetmelikleri başta olmak üzere 9 farklı ülkenin 16 farklı periyod formülleri kullanılarak analitik bir çalışma ile periyod karşılaştırması yapılmıştır. Karşılaş̧ırmanın yorumlanabilir sonuçlar vermesi için bünyesinde herhangi bir düzensizlik bulunmayan çerçeve türü bir model bina seçilmiştir. Seçilen model için kat sayısı 2-3-5-7-9-11 olarak değiştirilmiştir. Çerçeveler ETABS programında modellenmiş ve programdan elde edilen sonuçlara göre periyod hesapları yapılmıştır. Karşılaşırımalarda deprem yönetmeliklerinde verilen periyod bağıntıları ve Rayleigh yöntemi kullanılmıştır. Yapılan karşılaştırmaya göre çatlamamış kesit kabulü ile 5 kata kadar Rayleigh formülüne göre elde edilen sonuçların 2018 yönetmeliğinde verilen yaklaşı periyod formülüne 0.82-1.09 oranlarında yaklaştığı fakat yaklaşık formülün daha yüksek sonuçlar verdiği görülmüştür. Bununla beraber kesitlerin çatlamış olduğu düşünülecek olursa Rayleigh formülüne göre elde edilen sonuçların yaklaşık yönteme göre 1.16-1.62 kat daha fazla sonuç verdiği görülmektedir. 5 kattan sonra ise söz konusu oranların sırasıyla 1.21-1.39 ve 1.82-2.10 oranlarında değiştiği gözlenmiştir.
\end{abstract}

Anahtar kelimeler: Betonarme Bina, Periyod, Dünya Yönetmelikleri, 2018 Türk Deprem Yönetmeliği, Çatlamış Kesit

\section{Investigation of Periods of Frame Type Reinforced Concrete Buildings According to Different Empirical Approach}

\begin{abstract}
The behavior of a structure under the effect of an earthquake is generally dependent on the mass and lateral stiffness of the structure. Apparently, the dynamic character of the structure will obviously not depend on just two parameters. However, due to the difficulty of calculating the period together with other factors, approximate methods have been given in the literature. The most widely accepted method of these is the first natural vibration period equation that is proposed by Rayleigh. In this paper period comparisons were made with 16 different period formulas of 9 different countries such as 1998, 2007 and 2018 Turkish Earthquake Code with an analytical study. In order to give explainable results of the comparison, a model frame type building without any irregularity was chosen. The story number for the selected model has been changed as 2-3-5-7-9-11. The frames were modeled in the ETABS program and period calculations were made according to the results that get from the program. In comparison, empirical period formulation in earthquake codes and Rayleigh method were used. According to the comparison made, the results obtained according to the Rayleigh formula up to 5 stories with the cracked section acceptance approach to the approximate period formula given in the regulation of 2018 at the ratio of $0.82-1.09$, but the approximate formula gives higher results. However, if the cross-sections are thought to be cracked, the results obtained according to the Rayleigh formula show 1.16-1.62 times more results than the approximate method. After the 5 stories, the proportions changed into the ratios of 1.21-1.39 and 1.82-2.10 respectively.
\end{abstract}

Keywords: Reinforced concrete building, Period, World Earhquake Codes, 2018 Turkish Earthquake Regulations, Cracked Section

\footnotetext{
*Sorumlu yazar: mharslan@selcuk.edu.tr

Geliş Tarihi: 30.10.2018, Kabul Tarihi: 13.03.2019
} 


\section{Giriş}

Bir binanın deprem etkisi altında analizi için yapının doğal titreşim periyodunun bilinmesi gerekmektedir. Çok karmaşık olmayan yapıların deprem hesabında kullanılan eşdeğer deprem yükü yöntemine göre yapıya gelecek olan deprem yükü yapının doğal titreşim periyodu (ya da birinci mod periyodu) ile direkt ilgilidir. Tüm yapı ve deprem yönetmeliklerinde periyod değerinin hesaplanması için yaklaşık formüller verilmiştir. Bununla beraber yönetmeliklerde ayrıca yaklaşık formüller yerine, temelde yapının hareketi sırasında potansiyel enerjinin kinetik enerjiye olan eşitliği prensibinden ortaya çıkan Rayleigh oranı gibi, kesin değere oldukça yakın değerler veren formüller kullanılmaya da başlanmıştır. Yapılar üzerinde yapılan yapı sağlı̆̆ izleme çalışmaları gerçek yapılarda deneysel olarak hesaplanan periyod değeri ile analitik olarak hesaplanan ve "kesin" olarak nitelendirilen periyod değerleri arasında çok önemli farklılıklar bulunduğunu ortaya çıkarmıştır. Bunun en önemli nedeni ise hesaplarda kabul edilen kütle ve rijitlik değerleri ile bu değerlerin yapı içinde dağılımının kabul edilenden oldukça farklı olmasıdır. Ayrıca yapıda bulunan bölme duvar gibi rijitliği artıcı elemanlarda çoğu zaman analitik hesaplamalarda ihmal edilmektedir. Örneğin literatürde doğal titreşim periyodunun hesabı için yapılan çalışmalardan [1-4] yapı doğal titreşim periyodunun dolgu duvarların varlığı ile önemli olarak azaldığı görülmüştür. Yapının sönüm oranı, yapının türü, rijitliğin yapı içinde dağılımı da yine yapının periyodunu değiştiren diğer parametrelerdir.

Yapıların deprem analizi için izlenen prosedür deprem yönetmeliklerinde tarif edilmiştir. Deprem yönetmeliklerinde tanımlanan prosedüre göre çok yüksek olmayan ve düzenli yapıların deprem hesabında öncelikle yapının doğal titreşim periyodu bulunur. Ardından depreme verdiği bir cevap olan periyoda bağlı olarak yapıya gelecek olan tasarım ivme değeri ile yapının kütlesinin çarpılmasıyla yapıya etkiyecek elastik deprem kuvveti hesaplanmış olur. Görüldügü gibi yapıya gelecek olan deprem kuvveti periyodun bir fonksiyonudur. $\mathrm{Bu}$ nedenle deprem kuvvetinin belirli bir doğrulukta hesaplanabilmesi ancak periyodun belirli bir doğrulukta tahmin edilebilmesine bağlıdır.

Periyod hesabında temel ve etkili iki parametrenin doğru tespit edilmesi çok önemlidir. Bunlardan birisi salınım sırasında yapının etkin kütlesidir. Yönetmeliklerde deprem sırasında baz alınacak olan kütle ile ilgili çeşitli yaklaşımlar vardır. Bir diğer parametre olan yapının yatay rijitliği ise kütleye göre daha karmaşık bir yapıdadır. Yapıda artan deformasyonlarla beraber yapı elemanlarında meydana gelen çatlamalar ve elemanların rijitlik tanımlamalarındaki zorluklar bu parametrenin hesabını zorlaştırmaktadır. Örneğin Türk deprem yönetmeliğinde 1998 ve 2007 versiyonlarında [5, 6] tasarım için periyod hesabında elemanların rijitlik hesaplarında kesitlerde meydana gelen çatlama düşünülmez iken 2018 deprem yönetmeliğinde [7] elemanların türüne göre değişik oranlarda çatlama ve rijitlik kayıpları önerilmektedir. Bu durum yapının hesaplanan periyodunda değişikliğe ve dolayısıyla tasarım kuvvetlerinin ve deplasman değerlerinin değişmesine neden olmaktadır. Bununla beraber yönetmeliklerde periyod hesabı için farklı bağıntıların da verilmiş olması yine yapının periyod hesabında önemli farklılıklara neden olmaktadır.

Deprem yönetmeliklerinde verilen yaklaşık bağıntılar birbirinden farklı sonuçlar verebilmektedir. Çoğu zaman aynı ülkede kullanılan yönetmeliklerde bile periyod hesapları birbirinden farklı olabilmektedir. Örneğin ABD'de ASCE 7-16 [8] ve UBC-1997 [9] standartlarındaki periyod hesaplarında farklı denklemler önerilmiştir. Benzer durum Türkiye'de 1998, 2007 ve 2018 deprem yönetmeliklerinde de vardır.

Deprem yönetmeliklerinde kullanılan yaklaşımlar aynı teorik altyapıya bağlı olarak çıkarılmış olduğu için periyod hesabında kalıp ampirik yaklaşım aynıdır. Örneğin tüm yönetmeliklerde [9-12] yapı doğal titreşim periyodu Eşitlik 1'deki gibi ifade edilmektedir. Burada, yapı türüne bağlı olarak kullanılan katsay1 $(\alpha)$, bina yüksekliğini ifade eden katsayı $(H)$ ve tüm yönetmeliklerde değeri $3 / 4$ olan sabit bir kat sayı $(\beta)$ kullanılmaktadır.

$T=\alpha \cdot H^{\beta}$

Yönetmeliklerde verilen bu bağıntılardan bulunan periyod değerleri yukarıda açıklanan sebeplerden dolayı gerçekte hesaplanandan daha büyüktür. Örneğin Hong ve Hwang[13] ile Goel ve Chopra [14] yapmış oldukları çalışmada bunu ortaya koymuşlardır.

$\mathrm{Bu}$ çalışmada ise betonarme çerçeve türü yapıların periyodlarının hesabında kullanılan periyod hesaplarının örnek olarak seçilen bir plan türü üzerinden irdelemesi yapılmıştır. Çalışmanın temel 
motivasyonunu 2007 ve 2018 Türk Deprem Yönetmeliklerinde verilen periyod formüllerinin karşılaştırması oluştursa da çalışmada ASCE ve EC8 [15] gibi yönetmelikler ile Rayleigh yöntemi ile bulunan sonuçlar da karşılaştırılmıştır. Bu bağlamda karşılaştırmanın daha kolay yorumlanabilir sonuçlar vermesi için bünyesinde herhangi bir düzensizlik bulunmayan çerçeve türü bir model bina seçilmiştir. Seçilen model için kat sayısı 2-3-5-7-9-11 olarak değiştirilmiştir. Çerçeveler ETABS programında modellenmiş ve programdan elde edilen sonuçlara göre periyod hesapları yapılmıştır.

\section{Yönetmeliklerde Yer Alan Periyod Denklemleri}

Yapıların eşdeğer deprem yükü yöntemine göre tasarımında 1.mod hâkim periyod olarak dikkate alınmaktadır. Bu periyodun hesabında farklı yönetmelikler yaklaşık formüller önermektedir. Literatürde gerçek yapılar üzerinde yapılan dinamik deneylerin yönetmeliklerde verilen formüllerden oldukça farklı periyod değerleri verdiği bilinmektedir [1,3]. Periyodun doğru hesaplanmasının eşdeğer deprem yükü yöntemine göre önemi çok büyüktür. Zira yönetmeliklerde deprem sırasında yapıya etki edecek olan elastik ivme değeri yapının periyoduna bağlı olarak bir spektrum grafiği üzerinden hesaplanmaktadır. $\mathrm{Bu}$ önemden dolayı yönetmeliklerde yaklaşık formüllerin yanında Rayleigh\&Ritz tarafından 1877 ve 1909 yıllarında önerilen [16] literatürde Rayleigh metodu olarak geçen formül kullanılmaktadır. Rayleigh metodu birinci mod titreşimi için oldukça tutucu sonuçlar vermektedir. Yönetmeliklerde yer alan yaklaşık formüller genellikle Rayleigh tarafindan önerilen formüllere göre daha küçük sonuçlar vermektedir. Bu farkın en önemli nedeni, analitik hesaplarda göz önüne alınmayan dolgu duvarların rijitliği arttırıcı etkisidir. Dolayısıyla binanın gerçek özel periyodu analitik olarak hesaplanan değerden küçüktür; yani, analitik olarak hesaplanan periyod değeri güvensiz yönde kalmaktadır. Bu durum yaklaşık özel periyod formüllerini yeniden gündeme getirmiş ve son yıllarda hazırlanan birçok çağdaş deprem yönetmeliğinde, analitik olarak hesaplanan değere göre oldukça küçük periyod değerleri veren yaklaşık formüller önerilmiştir.

Bu çalışmada, sırasıyla aşağıdaki yönetmeliklerde yer alan yaklaşık özel periyod formülleri, farklı kat sayısına sahip örnek yapıya uygulanarak irdelenmekte ve uygulamada karşılaşılabilecek olumsuzluklar üzerinde durularak bazı tavsiyelerde bulunulmaktadır. Aşağıda detayları açıklanan yönetmelik formüllerinden ilk üçü Türkiye'de son yirmi yıldır yürürlükte kalmış ve 2018 yılında yayımlanmış deprem yönetmelikleridir. Diğer formüller ise Amerika, Avrupa, İran, İsrail, Yunanistan ve Hindistan yönetmeliklerinden alınarak irdeleme yapılmıştır.

Türkiye'de 1998 yılında Afet Bölgelerinde Yapılacak Yapılar Hakkında Yönetmelik (ABYYHY 1998) adıyla yürürlüğe giren bu yönetmelikte Eşdeğer Deprem Yükü yönteminin (EDYY) uygulandığı tüm binaların 1.mod titreşim periyodu Eşt.2'de verilen Rayleigh formülüne göre hesaplanmaktadır. Ancak, birinci ve ikinci derece deprem bölgelerinde $\mathrm{H}_{\mathrm{N}} \leq 25 \mathrm{~m}$ koşulunu sağlayan binaların, üçüncü ve dördünce derece deprem bölgelerinde ise EDYY'nin uygulandığ tüm binaların birinci doğal titreşim periyodunun Eşt.3'de verilen yaklaşık yöntemle hesaplanmasına izin verilmiştir. Ancak birinci ve ikinci derece deprem bölgelerinde bulunan yapıların yüksekliklerinin $25 \mathrm{~m}$ 'den büyük olması durumunda ise Rayleigh formülünün kullanılması zorunluluğu bildirilmiştir. Burada, her bir katın kütlesi $\left(\mathrm{m}_{\mathrm{i}}\right)$, ilgili katın deplasmanı $\left(\mathrm{d}_{\mathrm{fi}}\right)$ ve ilgili kata gelen fiktif yük $\left(\mathrm{F}_{\mathrm{fi}}\right)$ kullanılarak periyot hesabi yapılmaktadir.

$$
\begin{aligned}
& T_{1}=2 \pi * \sqrt{\sum_{i=1}^{N} \frac{m_{i} * d_{f i}^{2}}{F_{f i} * d_{f i}}} \\
& \mathrm{~T}_{1} \approx \mathrm{T}_{1 \mathrm{~A}}=\mathrm{C}_{\mathrm{t}} * \mathrm{H}_{\mathrm{N}}{ }^{3 / 4}
\end{aligned}
$$

Burada $\mathrm{H}_{\mathrm{N}}$ değeri tabi zemin üzerinden olan toplam bina yüksekliğini temsil ederken, $\mathrm{C}_{\mathrm{t}}$ değeri binanın taşıyıcı sistemine bağlı olarak tanımlanan bir katsayıdır. Taşıyıcı sistemi sadece betonarme çerçevelerden veya diş merkez çaprazlı çelik perdelerden oluşan binalarda $C_{t}=0.07$, taşıyıcı sistemi sadece çelik çerçevelerden oluşan binalarda $C_{t}=0.08$, diğer tüm binalarda ise $C_{t}=0.05$ alınacağ 1 belirtilmiştir. $\mathrm{Bu}$ çalışmada betonarme çerçeveli yapılar incelendiğinden $\mathrm{C}_{t}=0.07$ olarak dikkate alınmıştır. 
a. Türkiye'de 2007 yılında kapsamlı bir değişiklikle yürürlüğe giren Deprem Bölgelerinde Yapılacak Binalar Hakkında Yönetmelik'de kullanılan hesap ve tasarım kurallarının birçoğu ABYYHY-1998 esas alınarak oluşturulmuştur. Bu iki yönetmelik incelendiğinde, aralarında bazı farkların olduğu bilinse de TDY-2007 yönetmeliğinin temelini ABYYHY-1998 yönetmeliği oluşturmaktadır. 2007 yönetmeliğinde periyod hesabında 1998 yönetmeliğinde var olan Rayleigh formülü olduğu gibi kullanılmaktadır. Ancak 2007 yönetmeliğindeki değişimlerden biri de amprik olarak hesap edilen periyod formülündeki değişimdir. 2007 yönetmeliği ile bodrum katlar hariç kat sayısı $\mathrm{N}>13$ olan binalarda doğal periyod, $0.1 \mathrm{~N}$ 'den daha büyük alınmayacağı belirtilmiştir. Bununla beraber bu yönetmeliğin mevcut yapıların performansının belirlenmesi kısmında kolon, kiriş ve perdelerin rijitliklerinin çatlamış kesit kabulü ile düşürülmesi gerektiğinden bahsedilmektedir.

b. TDY-2007 yönetmeliği yayımlandıktan 11 yıl sonra 2019 yılı Ocak ayında TBDY yönetmeliği köklü değişiklikler ile yürürlüğe girmiştir. Bu yönetmelik ile ABYYHY-1998 ve TDY-2007'de var olan Rayleigh formülü, yapıların doğal titreşim periyodunun hesabında kullanılmaya devam edilecektir. Ancak TDY-1998'de var olan ampirik formül katsayısı değiştirilerek bu yönetmeliğe dönüş yapılmıştır. Burada ampirik formülün kullanılabilmesi için ayrıca şartlar da getirilmiştir. Deprem tasarım sinıfı (DTS=1, 1a, 2, 2a) ve bina yükseklik sınıfı (BYS $\geq 6$ ) olan binalarda ve DTS=3, 3a 4, 4a olan tüm binalarda hâkim doğal titreşim periyodu Rayleigh formülünden hesaplanmaksızın, doğrudan Eşt.4'de verilen ampirik $\mathrm{T}_{\mathrm{PA}}$ olarak alınabileceği belirtilmiştir.

$$
\mathrm{T}_{\mathrm{PA}}=\mathrm{C}_{\mathrm{t}}{ }^{*} \mathrm{H}_{\mathrm{N}} 3 / 4
$$

Burada taşıyıcı sistemi sadece betonarme çerçevelerden oluşan binalarda $C_{t}=0.1$, çelik çerçevelerden veya çaprazlı çelik çerçevelerden oluşan binalarda $\mathrm{C}_{\mathrm{t}}=0.08$, diğer tüm binalarda ise $\mathrm{C}_{\mathrm{t}}=0.07$ alınacağı belirtilmiştir. $\mathrm{Bu}$ çalışmada betonarme çerçeveli yapılar incelendiğinden $\mathrm{C}_{\mathrm{t}}=0.1$ olarak alınmıştır. Bununla beraber TBDY-2018'de en radikal farklılı̆̆ın yeni yapılacak ve mevcut yapıların periyod hesabında kolon, kiriş ve perdelerin rijitliklerinin çatlamış kesit kabulüne göre yapılmasının olduğu görülmektedir.

c) Mevcut Amerikan yönetmeliği olan ASCE 7-16, daha önceki versiyonları olan ASCE 7-02, 7-05, 710 yönetmeliklerinde olduğu gibi Rayleigh periyodunu kullanmamaktadır. Yaklaşı periyod hesabı 2 farklı ampirik formül ile gerçekleştirilmektedir. Birincisi Eşt.5'de verilen ve aynı zamanda TDY2007'de kullanılan formülün aynısıdır. Ancak burada kat sayısının $\mathrm{N}<12$ olması şartı getirilmiştir. İkincisi ise Eşt.6' da ifade edilen ve diğer yönetmeliklerde de olan ampirik formülün benzeridir.

$$
\begin{aligned}
& \mathrm{T}=0.1 \mathrm{~N} \\
& \mathrm{~T}_{\mathrm{a}}=\mathrm{C}_{\mathrm{t}} * \mathrm{H}_{\mathrm{N}}^{\mathrm{x}}
\end{aligned}
$$

Burada yapının türüne bağlı olarak ASCE 7-16 yönetmeliğinde toplam beş adet $\mathrm{C}_{\mathrm{t}}$ ve $\mathrm{x}$ değerleri tablo halinde verilmektedir. Bunlardan bazıları, moment aktaran çelik çerçeveli sistemler için $\mathrm{C}_{\mathrm{t}}=0.0724$ $\mathrm{x}=0.8$ verilmişken, betonarme çerçeve sistemlerde $\mathrm{C}_{\mathrm{t}}=0.0466 \mathrm{x}=0.9$ olarak dikkate alınması gerektiğ $\mathrm{i}$ belirtilmiştir. İlgili tablodaki sınıfa girmeyen diğer tüm yapılar için ise $C_{t}=0.0488 \mathrm{x}=0.75$ alınması gerektiği ifade edilmiştir. Bu çalışmada betonarme çerçeveli yapılar incelendiğinden $\mathrm{C}_{\mathrm{t}}=0.0466, \mathrm{x}$ ise 0.9 olarak alınmıştır.

d) Bir diğer Amerikan bina yönetmeliği olan ve 1997 versiyonundan sonra yürürlükten kalkan Uniform Building Code [9]'de de Rayleigh formülüne benzer doğal titreşim periyodunu hesaplama metodu kullanılmaktadır. Eşt.7'de kullanılan periyod formülü verilmiştir.

$$
T_{1}=2 \pi * \sqrt{\sum_{i=1}^{N} \frac{w_{i} * \delta_{i}^{2}}{F_{i} * \delta_{i} * g}}
$$


Burada her kata uygulanan yatay kuvvet $\left(\mathrm{F}_{\mathrm{i}}\right)$, uygulanan yatay kuvvete bağlı oluşan deplasman

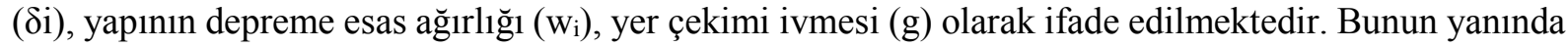
tüm binalarda uygulanabilecek yaklaşı periyod hesabında kullanılabilecek ampirik formül verilmektedir. Eşt. 8 diğer yönetmeliklerdeki ampirik formüllere bezerdir.

$$
\mathrm{T}=\mathrm{C}_{\mathrm{t}}{ }^{*} \mathrm{H}_{\mathrm{N}} 3 / 4
$$

Burada çelik çerçeveli yapılar için $\mathrm{C}_{\mathrm{t}}=0.0853$, betonarme çerçevelerden oluşan binalarda ve eksantrik takviyeli çerçevelerde $C_{t}=0.0731$, diğer tüm binalar için ise $C_{t}{ }^{\prime}$ nin 0.0488 alınabileceği ifade edilmiştir. Bu çalışmada betonarme çerçeveli yapılar incelendiğinden $C_{t}$ değeri 0.0731 olarak alınmıştır.

e) Avrupa yönetmeliği olan Eurocode 8 [15]'in güncel hali olan 2004 versiyonunda da doğal titreşim periyodu tayininde Rayleigh formülü kullanılmaktadır. Yaklaşık ampirik formül için ise bina yüksekliğinin 40 m'ye kadar olan kısmı için Eşt.9'da verilen formülün kullanılabileceği ifade edilmiştir. Formüldeki H değeri, temelden ya da rijit bodrum seviyesi üzerinden hesaplanan toplam yüksekliği belirtmektedir. $C_{t}$ değeri moment aktaran çelik çerçeveli sistemlerde 0.085 , betonarme çerçevelerde ve eksantrik takviyeli çerçevelerde 0.075 , diğer tüm yapılarda ise 0.050 alınabileceği belirtilmiştir.

$$
\mathrm{T}=\mathrm{C}_{\mathrm{t}}{ }^{*} \mathrm{H}^{3 / 4}
$$

f) İran yönetmeliğinde [17]'de UBC-1997'deki Rayleigh formülü doğal titreşim periyodunu hesaplamada kullanılmaktadır. Eşt.10 ve Eşt.11'de dolgu duvarın çerçeve sisteme bitişik ve ayrı olması durumu için iki farklı ampirik formül verilmiştir. Eğer moment aktaran çerçeve sistemlerde dolgu duvarlar çerçeveye bitişikse, aşağıdaki formülden elde edilen periyod değerinin \%80'inin alınacağı belirtilmektedir.

$$
\mathrm{T}=0.07 * \mathrm{H}^{3 / 4}
$$

Eğer moment aktaran çerçeve sistemlerde dolgu duvarlar çerçeveye bitişik değilse

$$
\mathrm{T}=0.07 * \mathrm{H}^{3 / 4}
$$

Geriye kalan diğer tüm binalarda ise kullanılacak periyod formülü Eşt.12'deki gibi verilmiştir.

$$
\mathrm{T}=0.05 * \mathrm{H}^{3 / 4}
$$

Burada $\mathrm{H}$ metre cinsinden temel seviyesinden itibaren toplam bina yüksekliği olarak ifade edilmektedir. Ayrıca eğer çatı katının ağırlığı kat ağırlığının \%25'inden fazlaysa çatı katı yüksekliği de toplam yüksekliğe dâhil edilmesi gerektiği belirtilmiştir. Bu çalışmada betonarme çerçeveli yapılar incelendiğinden $\mathrm{C}_{\mathrm{t}}=0.07$ olarak alınmıştır.

g) Yunanistan yönetmeliğinde [18]'de doğal titreşim periyodu hesabında Rayleigh formülü kullanılmaktadır. Dikdörtgen plan görüntüsüne sahip binalar için aşağıdaki Eşt.13 kullanılarak temel periyodun bulunabileceği belirtilmektedir.

$$
T=0.09 * \frac{\mathrm{H}}{\sqrt{\mathrm{L}}} * \sqrt{\frac{\mathrm{H}}{\mathrm{H}+\rho * \mathrm{~L}}}
$$

Burada, H: Toplam bina yüksekliğini, L: Deprem analizi yapılan doğrultudaki bina uzunluğunu ve $\rho$ : Deprem hesabı yapılan doğrultudaki toplam duvar en kesit alanının, toplam kolon ve duvar en 
kesit alanları toplamına oranıdır. Bu çalışmada binada dolgu duvarların olması durumu ve ihmal edilmesi durumuna göre iki farklı analiz yapılmışıtır. Dolgu duvarın olması durumunda $\rho=0.4$ olarak alınmıştır.

h) İsrail Yönetmeliğinde [19] eşdeğer deprem yükü hesabının uygulanabileceği yapılarda yapının doğal titreşim periyodu için aşağıdaki eşitlikler kullanılabilir. Eğer yapı, betonarme veya eksantrik sertleştirilmiş çelik çerçevelerden oluşuyorsa Eşt.14, yalnızca çelik çerçeveli bir sistem ise Eşt.15, bunların dışındaki yapılar için ise Eşt.16'nın kullanılabileceği belirtilmektedir. H, metre cinsinden ifade edilmektedir. Bu çalışmada betonarme çerçeveli yapılar incelendiğinden periyod hesabındaki ilgili çarpan 0.075 olarak alınmıştır.

$$
\begin{aligned}
& \mathrm{T}=0.075^{*} \mathrm{H}^{3 / 4} \\
& \mathrm{~T}=0.085^{*} \mathrm{H}^{3 / 4} \\
& \mathrm{~T}=0.050^{*} \mathrm{H}^{3 / 4}
\end{aligned}
$$

1) Hindistan yönetmeliği [20]' de İsrail ve Eurocode 8 yönetmeliklerinde olduğu gibi yapıların yaklaşık doğal titreşim periyodlarının hesabında aynı formülleri kullanmaktadır. Ancak Hindistan yönetmeliğinde yaklaşı periyod hesabında moment aktaran çerçeve binalarda dolgu duvarın olmaması durumu düşünülerek aşağıdaki iki ampirik formül önerilmiştir. Eşt.17 betonarme binalar için, Eşt.18 ise çelik çerçeveli binalar için önerilmektedir. Burada moment aktaran tuğla dolgulu tüm binalar için diğer yönetmeliklerden farklı bir formül Eşt.19 ile önerilmektedir. Burada h, binanın metre cinsinden yüksekliğini, d ise binanın deprem yönüne bağlı olarak dikkate alınan plan düzlemindeki metre cinsinden uzunluğunu temsil etmektedir. Hesaplamalarda 0.075 katsayısı kullanılmıştır. Deprem doğrultusundaki uzunluk(d) olarak ise $15 \mathrm{~m}$ alınmıştır.

$$
\begin{aligned}
& \mathrm{T}_{\mathrm{a}}=0.075^{*} \mathrm{~h}^{3 / 4} \\
& \mathrm{~T}_{\mathrm{a}}=0.085^{*} \mathrm{~h}^{3 / 4} \\
& \mathrm{~T}_{\mathrm{a}}=\frac{0.09}{\sqrt{\mathrm{d}}} * h
\end{aligned}
$$

Yukarıda belirtilen tüm yönetmeliklerde yapının doğal titreşim periyodu yapı yüksekliğinin bir fonksiyonudur. Bununla beraber yapının taşıyıcı sistem türüne göre formüllerdeki katsayılar değişmektedir. Hindistan ve Yunanistan yönetmeliklerinde yapıda bulunan dolgu duvara göre formül değişmektedir.

\section{Analitik Çalışma}

Bu çalışmada Deprem Yönetmeliklerinde verilen ve yukarıda özetlenen periyod formülleri ve periyod hesabına etkin parametreler analitik bir çalışma yapılarak karşılaş̧ırılmıştır. Karşılaştırmanın daha rahat yorumlanabilir sonuçlar vermesi için bünyesinde herhangi bir düzensizlik bulunmayan çerçeve türü bir model bina seçilmiştir. Seçilen model için kat sayısı 2-3-5-7-9-11 olarak değiştirilmiştir. Çerçeveler ETABS programında modellenmiş ve programdan elde edilen sonuçlara göre periyod hesapları yapılmıştır. Tasarlanan modelde kat yüksekliği 3.5 metre seçilmiştir. Planda her iki yönde toplam uzunluğu 15'er metre olan binanın aks aralıkları 5 metre olarak belirlenmiştir. Şekil 1'de modellenen binaların kat planı ve 3D modelleri verilmiştir. 


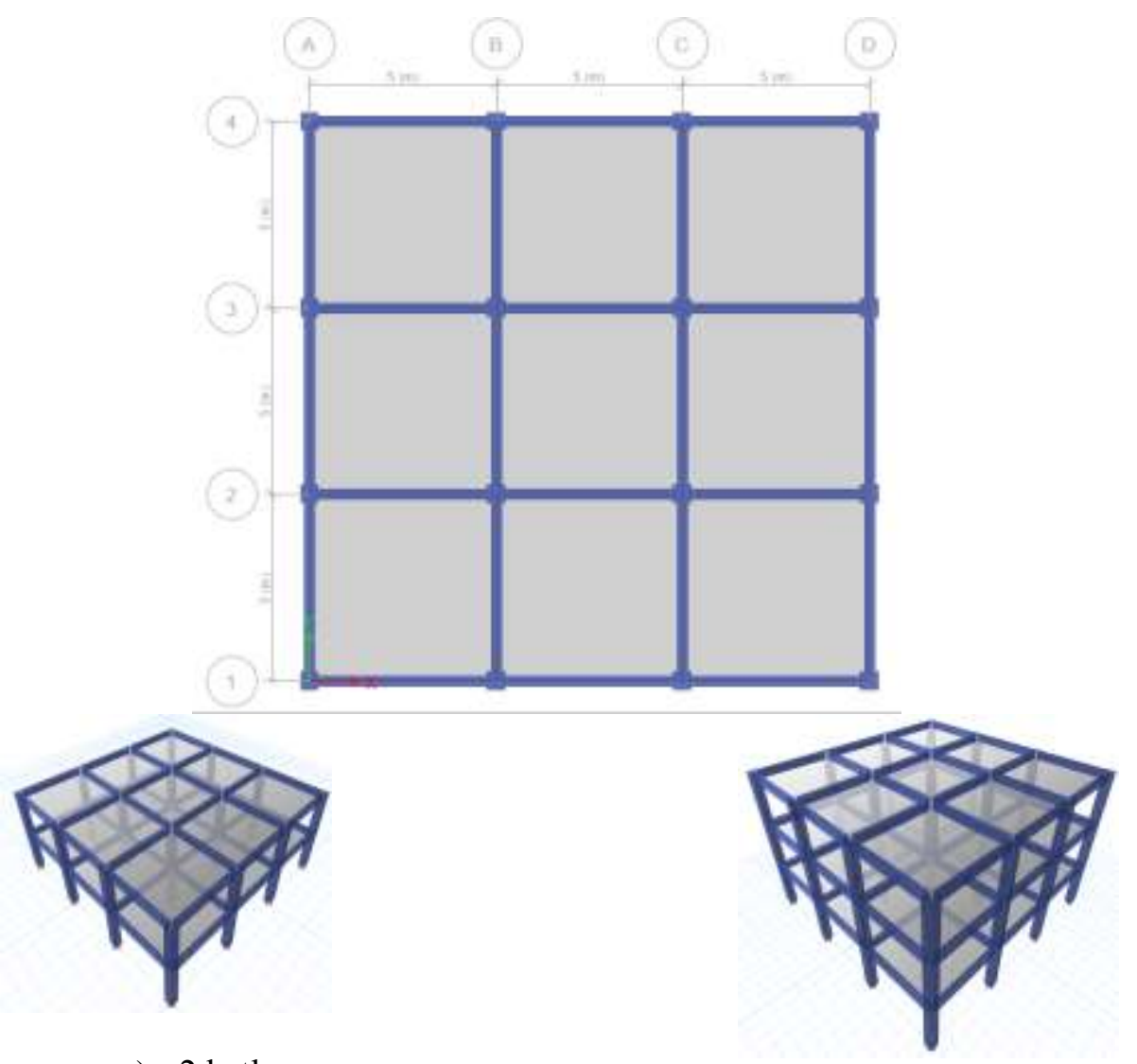

a) 2 katl1

b) 3 katl1

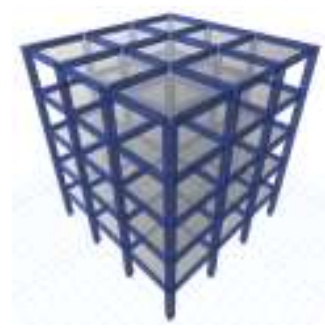

c) 5 katl

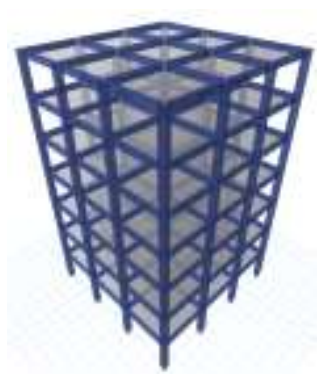

d) 7 katl 1
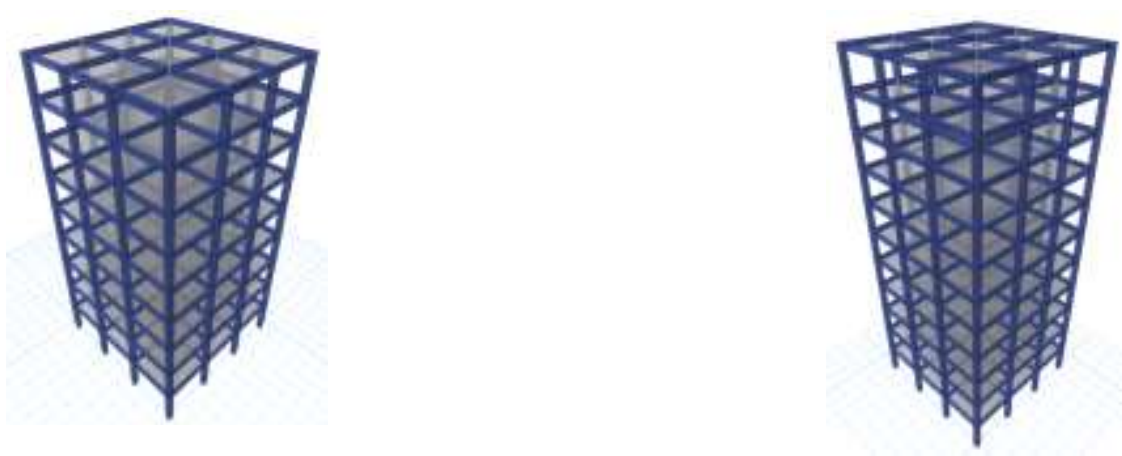

e) 9 katl 1

f) 11 katl1

Şekil 1. Modellenen binanın plan ve 3D görünümü 
Taşıyıcı sistemde kesitler kolonlar için $50 / 50 \mathrm{~cm}$ ve kirişler için $25 / 50 \mathrm{~cm}$ olarak belirlenmiştir. Kolon ve kiriş kesitleri her katta sabit aynı seçilmiş̧ir. Temel ankastre olarak modellenmiş ve döşeme kalınlığı ise $15 \mathrm{~cm}$ alınmıştır. Yapı geometrisi belirlenmiş olan sistemde C30 sınıfi beton ve S420 sınıfı donatı kullanılmıştır. Binanın taşıyıcı sistemi, deprem yüklerinin süneklik düzeyi yüksek betonarme çerçevelerle birlikte taşındığı sistem olarak dikkate alınmıştır. Kat planında düzenli bir taşıyıcı eleman yerleşimi yapılarak düzensizliklerin etkisi göz önünde bulundurulmamıştır.

Döşeme üzerindeki ölü ve hareketli yükler sırasıyla $\mathrm{g}=2.2 \mathrm{kN} / \mathrm{m}^{2}$ ve $\mathrm{q}=2.0 \mathrm{kN} / \mathrm{m}^{2}$ olarak her katta sabit olacak şekilde alınmıştır. Ayrıca binada $20 \mathrm{~cm}$ 'lik dış duvar yükü ve $10 \mathrm{~cm}$ 'lik iç duvar yükü sırasıyla $g_{d}=12 \mathrm{kN} / \mathrm{m}$ ve $g_{d}=9 \mathrm{kN} / \mathrm{m}$ olacak şekilde hesaba katılmıştır. Yapılan analizlerde, dolgu duvarların betonarme çerçeve sisteme temas etmediği düşünülmüş olup hesaplamalarda yalnızca ölü yük olarak dikkate alınmıştır.

Modelleme sonucunda elde edilen periyod değerleri Tablo 1-Tablo 3 ve Şekil 2-Şekil 5 olacak şekilde verilmiştir. Tablo 1'de 1998, 2007 ve 2018 Türk Deprem Yönetmeliklerine göre hesaplanmış yapı periyodları yer almaktadır. Tablodan görüleceği gibi Rayleigh yöntemine göre periyod hesabı 2007 ve 2018 deprem yönetmeliklerinde iki farklı şekilde yapılmıştır.* ile işaretlenmiş olan periyod kesitlerde deprem sırasında meydana gelecek olan çatlamaya göre bulunmuştur. Kesitlerde çatlama ile oluşacak atalet kayıpları TDY-2007 ve TBDY-2018'de verilmiştir. Genel olarak çatlamanın kirişler ataletlerinde daha büyük bir azaltıcı etki yapacağı yönetmeliklerde belirtilmiştir. TDY-2007'de kirişler için kesit atalet kaybının \%60 kolon ve perdelerde ise eksenel yüke bağlı olarak \%20 \%60 aralığında olması gerektiği söylenmektedir. TBDY-2018' de ise kirişlerde kaybın $\% 65$ kolonlarda $\% 30$ perdelerde ise $\% 50$ olması gerektiği söylenmektedir. Özellikle Rayleigh yöntemine göre yapılan çatlamış kesit varsayımı ile yapılan hesapların diğer ampirik yöntemlere göre 2.5-3.0 kata yakın daha büyük değer verdiği görülmektedir. Gerçek yapılarda dolgu duvarların varlığı ve bitişik nizam etkisi ile yapının salınım sırasındaki kütlesinin hesap edilen teorik kütleye göre daha az olma ihtimali gerçekte periyodun daha az olacağı anlamına gelmektedir. Bu durumda yönetmelikte verilen yaklaşık denklemlerin Rayleigh formülüne göre daha tutucu sonuçlar vermesi doğaldır.

Tablo1. Türk Deprem Yönetmeliklerine göre bina birinci mod periyodları ABYYHY-1998

Bina

TDY-2007

TBDY-2018

\begin{tabular}{ccc|ccc|cc}
\cline { 2 - 7 } $\begin{array}{c}\text { Yüksekliği } \\
(\boldsymbol{m})\end{array}$ & $\mathrm{T}_{1 \mathrm{~A}}=\mathrm{C}_{\mathrm{t}} * \mathrm{H}_{\mathrm{N}}{ }^{3 / 4}$ & Rayleigh & $\mathrm{T}_{\mathrm{P}=0.1 \mathrm{~N}}$ & Rayleigh & Rayleigh* & $\mathrm{T}_{\mathrm{PA}}=\mathrm{C}_{\mathrm{t}} * \mathrm{H}_{\mathrm{N}} 3 / 4$ & Rayleigh* \\
\hline $\mathbf{7}$ & 0.301 & 0.355 & 0.200 & 0.355 & 0.555 & 0.430 & 0.501 \\
$\mathbf{1 0 . 5}$ & 0.408 & 0.544 & 0.300 & 0.544 & 0.838 & 0.583 & 0.788 \\
$\mathbf{1 7 . 5}$ & 0.598 & 0.933 & 0.500 & 0.933 & 1.388 & 0.855 & 1.389 \\
$\mathbf{2 4 . 5}$ & 0.770 & 1.329 & 0.700 & 1.329 & 1.936 & 1.101 & 2.003 \\
$\mathbf{3 1 . 5}$ & 0.930 & 1.731 & 0.900 & 1.731 & 2.486 & 1.329 & 2.624 \\
$\mathbf{3 8 . 5}$ & 1.081 & 2.139 & 1.100 & 2.139 & 3.04 & 1.545 & 3.249 \\
\hline
\end{tabular}

Tablo 2 ve Tablo 3'de diğer yönetmeliklerin yaklaşımları verilmiştir. Tablo 2'de verilen yönetmelik formüllerinde dolgu duvarların varlığı düşünülmemektedir. Bu sonuçlara göre en tutucu periyod formülünün ASCE 7-16 tarafindan önerildiği görülmektedir. 


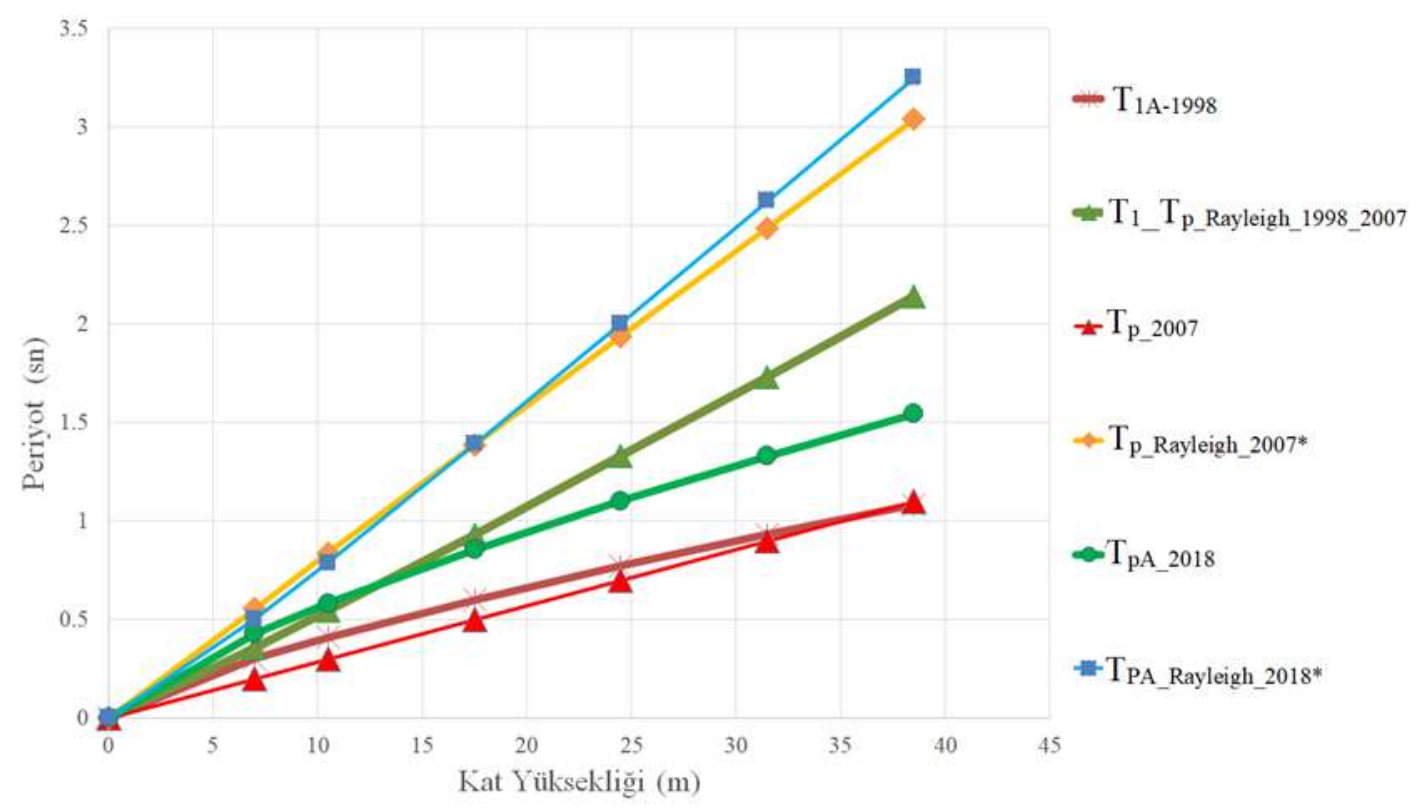

Şekil 2. Periyodların yapı yüksekliğine göre değiş̧imi

Tablo2. Dolgu duvarın dikkate alınmadığı yönetmeliklere ait periyod hesapları

\begin{tabular}{|c|c|c|c|c|c|}
\hline \multirow{2}{*}{$\begin{array}{c}\text { Bina } \\
\text { Yüksekliği } \\
\text { (m) }\end{array}$} & \multicolumn{2}{|c|}{ ASCE 7-16 } & \multirow{2}{*}{$\begin{array}{l}\text { UBC-1997 } \\
\mathrm{T}=\mathrm{C}_{\mathrm{t}} * \mathrm{H}_{\mathrm{N}}{ }^{3 / 4}\end{array}$} & \multirow{2}{*}{$\begin{array}{c}\text { EC-8/ İsrail ve } \\
\text { Hindistan } \\
\mathrm{T}=\mathrm{C}_{\mathrm{t}} * \mathrm{H}^{3 / 4}\end{array}$} & \multirow{2}{*}{$\begin{array}{l}\text { İRAN-2007 } \\
\mathrm{T}=\mathrm{C}_{\mathrm{t}} * \mathrm{H}^{3 / 4}\end{array}$} \\
\hline & $\mathrm{T}=0.1 \mathrm{~N}$ & $\mathrm{~T}_{\mathrm{a}}=\mathrm{C}_{\mathrm{t}} * \mathrm{H}_{\mathrm{N}}^{\mathrm{x}}$ & & & \\
\hline 7 & 0.200 & 0.200 & 0.367 & 0.322 & 0.301 \\
\hline 10.5 & 0.300 & 0.271 & 0.497 & 0.437 & 0.408 \\
\hline 17.5 & 0.500 & 0.398 & 0.729 & 0.641 & 0.598 \\
\hline 24.5 & 0.700 & 0.513 & 0.939 & 0.825 & 0.770 \\
\hline 31.5 & 0.900 & 0.619 & 1.134 & 0.997 & 0.930 \\
\hline 38.5 & 1.100 & 0.720 & 1.318 & 1.159 & 1.081 \\
\hline
\end{tabular}

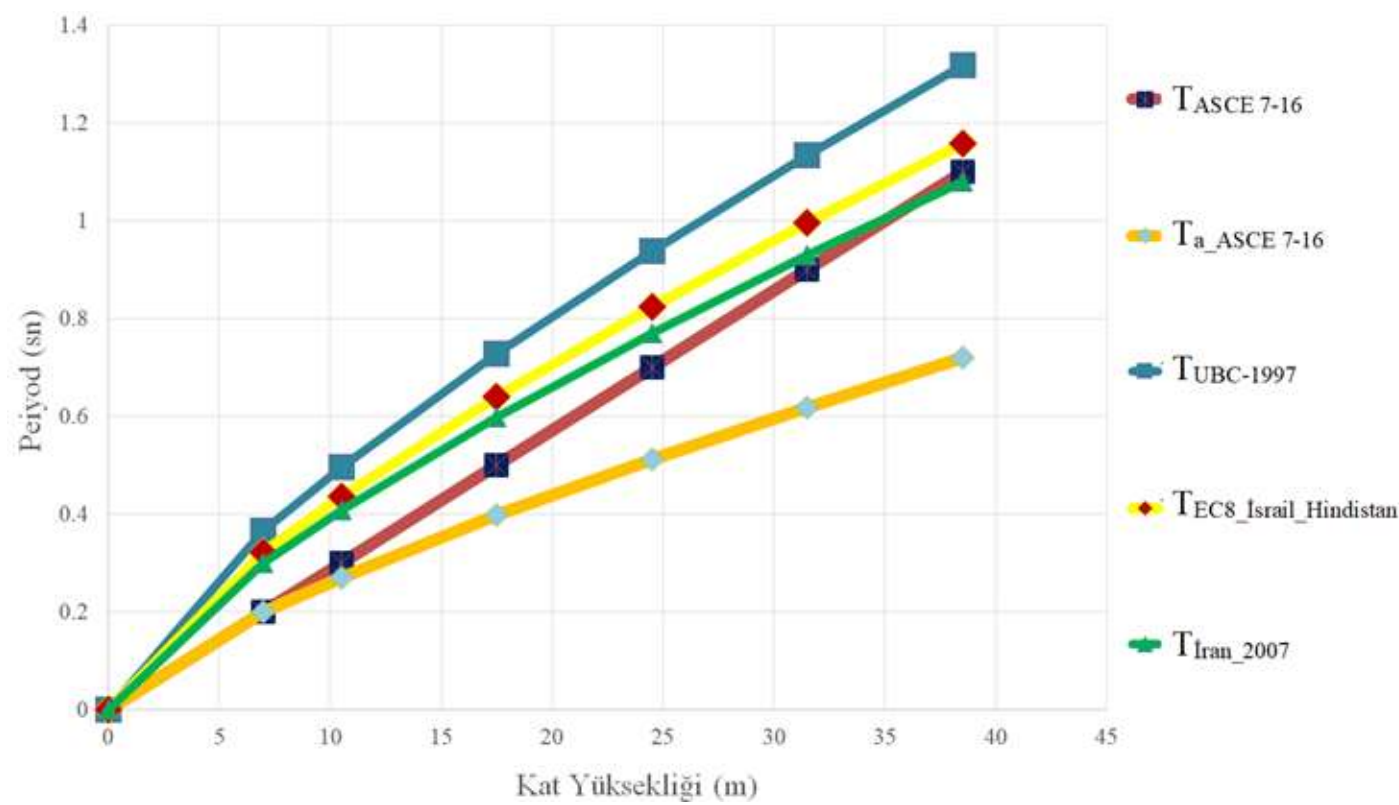

Şekil 3. Periyodların yapı yüksekliğine göre değişimi 
Tablo 3'de ise dolgu duvar varlığını düşünerek hazırlanmış olan Yunanistan ve Hindistan yönetmeliğine göre elde edilen değerler duvarlı ve duvarsız olmak üzere verilmiştir. Yunanistan yönetmeliğinin vermiş olduğu bağıntıya göre yapı yüksekliği arttıkça dolgu duvarın periyoda olan etkisi azalmaktadır. Tabloya göre 38.5 metre yükseklik için fark $\% 7$ iken 7 metre yüksekliğe sahip olan binada fark \%36'dır. Ama her hâlükârda dolgu duvar periyodu düşürücü etkiye sahiptir. Hindistan yönetmeliğinde de yine dolgu duvar periyodu düşürücü etkiye sahip olduğu görülmektedir fakat oranlar \%30 98 arasında değişmektedir. 38.5 metre yükseklik \%30 olan fark 7 metre yüksekliğe sahip olan binada \%30'a düşmektedir.

\begin{tabular}{|c|c|c|c|c|c|}
\hline \multirow{3}{*}{$\begin{array}{l}\text { Bina } \\
\text { Yüksekliği } \\
\quad(\mathbf{m})\end{array}$} & \multicolumn{3}{|c|}{ Yunanistan Yönetmeliği } & \multicolumn{2}{|c|}{ Hindistan Yönetmeliği } \\
\hline & \multirow{2}{*}{$\begin{array}{l}\text { Tuğla Duvarsız } \\
\qquad \mathrm{T}=0.09 * \frac{\mathrm{H}}{\sqrt{\mathrm{L}}}\end{array}$} & \multicolumn{2}{|c|}{ Tuğla Duvarlı } & \multirow{2}{*}{$\begin{array}{l}\text { Tuğla Duvarsız } \\
\mathrm{T}_{\mathrm{a}}=\mathrm{C}_{\mathrm{t}}{ }^{*} \mathrm{~h}^{3 / 4}\end{array}$} & \multirow{2}{*}{$\begin{array}{l}\text { Tuğla Duvarlı } \\
\mathrm{T}_{\mathrm{a}}=\frac{0.09}{\sqrt{\mathrm{d}}} * \mathrm{~h}\end{array}$} \\
\hline & & $\mathrm{T}=0.09 * \frac{\mathrm{H}}{\sqrt{\mathrm{L}}} * \sqrt{\mathrm{z}}$ & $\frac{H}{H+\rho * L}$ & & \\
\hline 7 & 0.162 & 0.119 & & 0.322 & 0.162 \\
\hline 10.5 & 0.243 & 0.194 & & 0.437 & 0.243 \\
\hline 17.5 & 0.406 & 0.350 & & 0.641 & 0.406 \\
\hline 24.5 & 0.569 & 0.510 & & 0.825 & 0.569 \\
\hline 31.5 & 0.731 & 0.670 & & 0.997 & 0.731 \\
\hline 38.5 & 0.894 & 0.832 & & 1.159 & 0.894 \\
\hline
\end{tabular}

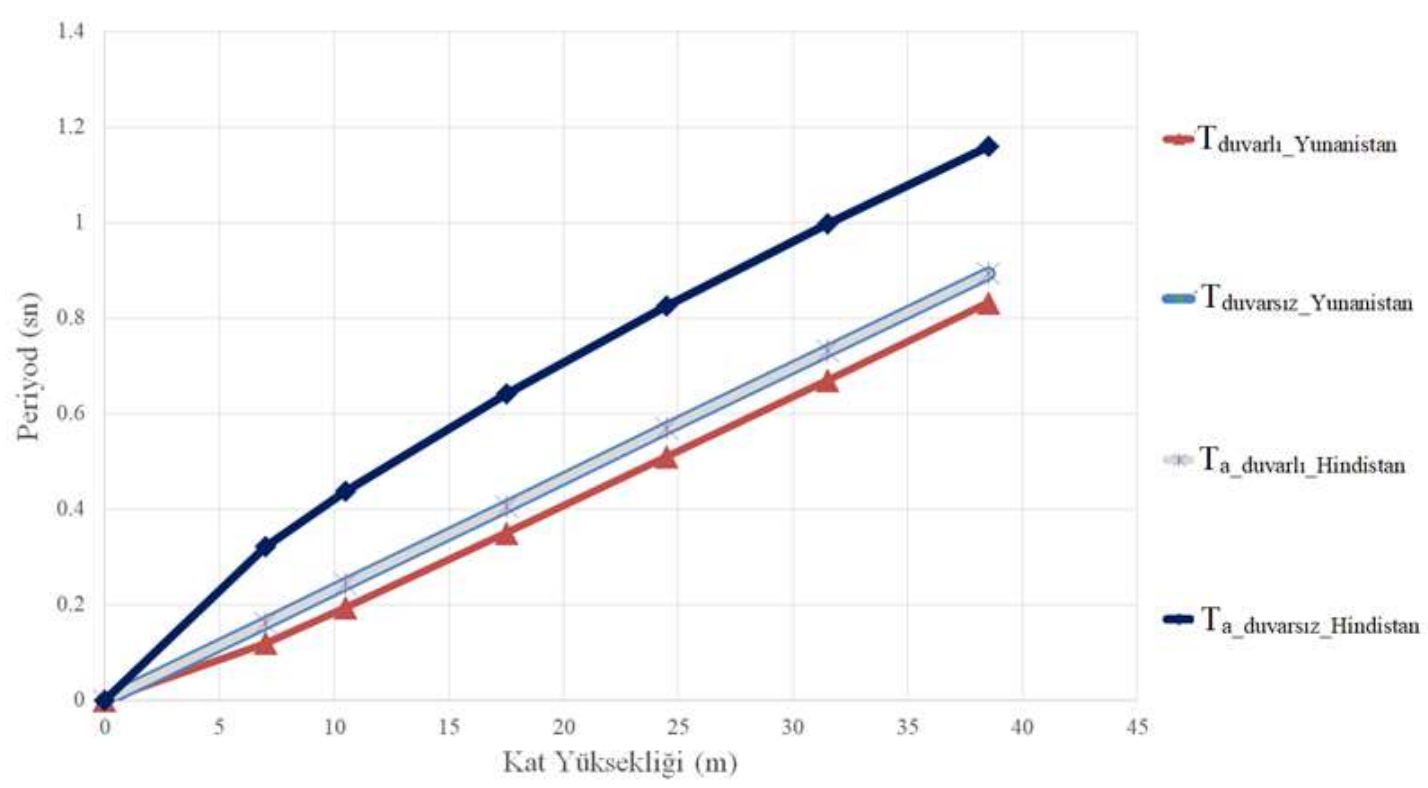

Şekil 4. Periyodların yapı yüksekliğine göre değişimi 


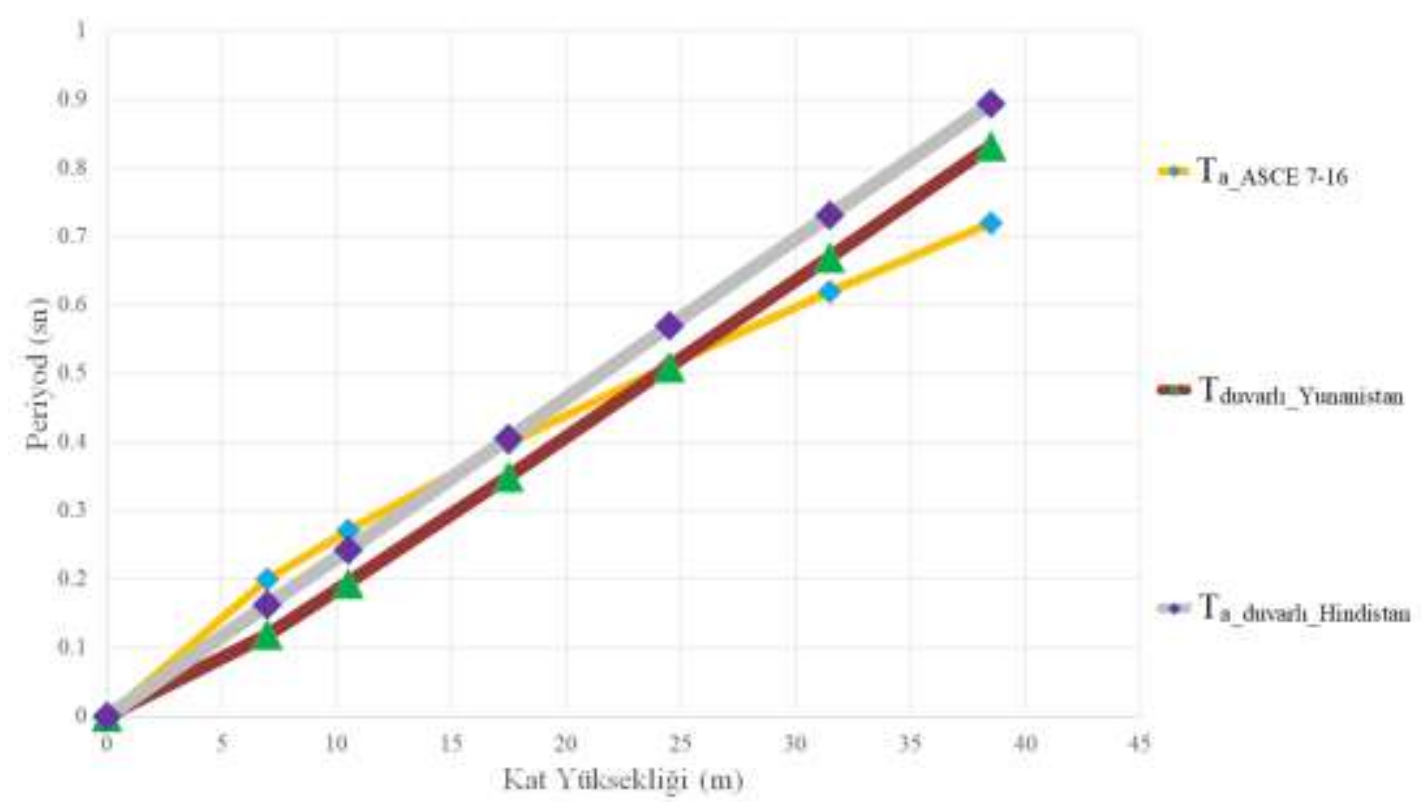

Şekil 5. ASCE 7-16 $\left(\mathrm{T}_{\mathrm{a}}=\mathrm{C}_{\mathrm{t}}{ }^{*} \mathrm{H}_{\mathrm{N}}{ }^{\mathrm{x}}\right)$ ile Dolgu duvarlı Yunanistan ve Hindistan Periyodlarının Yapı Yüksekliğine Göre Değişimi

\section{Sonuçlar ve Tartışma}

Yapılan bu çalışma ile 9 farklı yönetmelikte betonarme yapılar için verilen 16 farklı periyod yaklaşımı kıyaslanmıştır. Yapılan kıyaslamalara göre aşağıdaki sonuçlara ulaşılmıştır;

a) 1998, 2007 ve 2018 deprem yönetmeliklerinde ampirik periyod hesapları önemli oranda değişmektedir. Özellikle 2018 yönetmeliğinde bu değișimin etkisi daha fazla görülmektedir. Bunun temel sebebi periyod hesaplamalarında yönetmelikte yer alan çatlamış kesit kabulüdür. Örneğin 7 katlı bir betonarme bina için 1998 yönetmeliğine göre 1.081 sn olarak elde edilen periyod değeri, 2018 yönetmeliğinde 1.545 sn olarak bulunmaktadır.

b) 1998, 2007 ve 2018 yönetmeliklerinde verilen ampirik bağıntılar ile Rayleigh yöntemine göre bulunan periyod değerleri arasında çok önemli farklılıklar vardır. Rayleigh yöntemine göre bulunan periyod ile 1998 ve 2018 yönetmeliklerine göre bulunan periyod arasında bina yüksekliği arttıkça artan ve 1.17 1.98 arasında değişen bir oran vardır. Bulunan periyodlar farklı olsa bile 1998 yönetmeliği ile 2018 yönetmeliğine göre hesaplarda bu oran aynı olmaktadır.

c) 2018 yönetmeliğinde bahsedilen Rayleigh yöntemine göre bulunan periyod değeri ampirik $\mathrm{Ct}^{*} \mathrm{H}_{\mathrm{N}}{ }^{\mathrm{x}}$ formülüne göre bulunan periyod değerinin 1.4 katını aşamaz denilmektedir. Şu durumda 4 ve daha fazla katlı yapılarda (Yüksekliği 14 metreyi geçen) bir yapıda Rayleigh formülü devre dış1 kalmaktadır.

d) Rayleigh yöntemine göre bulunan periyod ile 2007 yönetmeliklerine göre bulunan periyod arasında bina yüksekliği arttıkça artan ve 1.78 1.94 arasında değişen bir oran vardır. 2007 yönetmeliğinde verilen çatlamış kesit oranlarına göre yapılan modelleme ile elde edilen Rayleigh periyodu ile $0.1 \mathrm{~N}$ bağıntısından bulunan periyod arasında tüm yükseklikler için 2.78 olarak belirlenen sabit bir oranı bulunmaktadir.

e) ASCE 7-16' de verilen $0.1 \mathrm{~N}$ yaklaşımı $\mathrm{Ct}^{*} \mathrm{H}_{\mathrm{N}}{ }^{\mathrm{x}}$ yaklaşımına göre bina yüksekliği arttıkça daha fazla artan bir seyir göstermektedir.

f) EUROCODE 8-2004, İsrail Yönetmeliği ve Hindistan Yönetmeliğinde verilen bağıntılar aynı olduğu için bulunan sonuçlarda aynıdır.

g) Tüm yönetmelikler içinde en katı değerlerin ASCE 7-16'da verilen $\mathrm{Ct}^{*} \mathrm{H}_{\mathrm{N}}{ }^{\mathrm{x}}$ yaklaşımı vermektedir. Bu durum özellikle Amerika'da yapılan alan çalışmaları ile elde edilen periyod değerlerine göre yönetmeliğin yapmış olduğu bir kalibrasyon olduğunu düşündürmektedir. Ayrıca tuğla duvarın varlığı düşünüldüğü zaman ASCE'nin önerdiği denklemin daha gerçekçi olduğu ortaya çıkmaktadır.

h) Yunanistan ve Hindistan yönetmeliklerine tuğla dolgu duvar olması ya da olmaması durumuna göre iki farklı çözüm yapılmıştır. Yönetmeliklere göre özellikle az katlı yapılarda tuğla dolgu duvarın rijitliğe olan etkisi daha fazladır. Tuğla dolgu duvar rijitliği önemli oranda artırmaktadır. Yunanistan 
yönetmeliğine göre 38.5 metre yükseklik için fark \%7 iken 7 metre yüksekliğe sahip olan binada fark \%36'dır. Benzer şekilde Hindistan yönetmeliğinde de oranlar 38.5 metre yükseklik için \%30, 7 metre yükseklik içinse \%30'a düşmektedir. Bu azalma oranları tartışmaya açıktır. Köse ve Karslıoğlu [21]'da 26.6 metre ile 42 metre arasında değişen binalarda tuğla duvar varlığı düşünülerek ve düşünülmeden yapılan modellemelere göre dolgu duvarlar \%2.86 ila \%5.20 arasında değişen azalmalara sebep olmuştur. Yapıların 10-13 katlı olması sebebiyle periyoddaki değişikliğin daha az olması normal karşılanabilir.

Çalışmadan elde edilen bulgular 1şı̆̆gnda nihai olarak şu sonuca ulaşılmıştır. Rijitlik ve kütle gibi tahmini kolay olmayan yapısal parametreler kullanılarak yapının doğal titreşim periyodunu gerçek davranışa yakın olarak hesaplamak oldukça iddialı bir yaklaşımdır. Bu nedenle yönetmeliklerin vermiş olduğu periyod hesaplarının mümkün olduğunca basitleştirilmesi karmaşı bir problemin rahat anlaşılması adına normal karşılanmaktadır. Bununla beraber binanın doğal titreşim periyodunun hesabı her ne kadar oldukça basit ampirik yaklaşımlarla ifade edilmiş olsa da elde edilen sonuçların farklılığı deprem hesabında baz alınan tasarım depremlerinin çok farklı seviyede olmasına da neden olmaktadır. Özellikle tuğla duvarların yapı periyoduna önemli etki yaptığı önerilen ampirik yaklaşımlarda da görülmektedir. $\mathrm{Bu}$ nedenle ileriki çalı̧̧malarda betonarme yapılarda meydana gelen çatlama etkisi mutlaka düşünülmelidir. Ayrıca dolgu duvar uzunluğun yanında, duvarın rijitlik, düşeyde ve yatayda (planda) kat içinde dizilimi vs. gibi etmenlerin periyod hesabında yerinin olması ve yapıda bulunan perde elemanlarının da bir parametreye bağlı olarak periyod formülünde ifade edilmeleri gerekmektedir.

\section{Kaynaklar}

[1] Crowley H., Pinho R. 2004. Period-Height Relationship for Existing European Reinforced Concrete Buildings. Journal of Earthquake Engineering, 8: 93-119.

[2] Crowley H, Pinho R. 2006. Simplified equations for estimating the period of vibration of existing buildings. First European conference on earthquake engineering and seismology.

[3] Kose M.M. 2009. Parameters affecting the fundamental period of RC buildings with infill walls. Engineering Structures, 31 (1): 93-102.

[4] Masi A., Vona M. 2009. Estimation of the Period of Vibration of Existing RC Building Types Based on Experimental Data and Numerical Results. Increasing Seismic Safety by Combining Engineering Technologies and Seismological Data, 207-225.

[5] ABYYHY. 1998. Afet Bölgelerinde Yapılacak Yapılar Hakkında Yönetmelik, Deprem Afetinden Korunma. http://www.resmigazete.gov.tr/eskiler/2007/07/20070714-7.htm. (Erişim Tarihi: 10.09.2018).

[6] TDY. 2007. Deprem Bölgelerinde Yapılacak Binalar Hakkında Yönetmelik. TC Çevre ve Şehircilik Bakanlığı, Afet İşleri Genel Müdürlüğü, Deprem Araştırma Dairesi (Erişim Tarihi: 10.09.2018).

[7] TBDY. 2018. Türkiye Bina Deprem Yönetmeliği, Deprem Etkisi Altında Binaların Tasarımı için Esaslar. http://www.resmigazete.gov.tr/eskiler/2018/03/20180318M1-2-1.pdf. (Erişim Tarihi: 10.09.2018).

[8] ASCE7-16. 2017. Minimum Design Loads and Associated Criteria for Buildings and Other Structures in Seismic Design Requirements for Building Structures Structural Engineering Institute. https://www.asce.org/asce-7/. p. 89-121 ( Erişim Tarihi: 10.09.2018).

[9] UBC-1997. Structural Design Requirements Earthquake Design. p. 9-22. (Erişim Tarihi: 10.09.2018)

[10] ATC-3-06. 1982. Tentative Provisions for the Development of Seismic Regulations for Buildings. https://www.atcouncil.org/pdfs/atc306.pdf. (Erişim Tarihi: 10.09.2018).

[11] CEN. 2004. Design of concrete structures, Part 1-1: General rules and rules for buildings. Brussels. https://www.phd.eng.br/wp-content/uploads/2015/12/en.1992.1.1.2004.pdf. (Erişim Tarihi: 10.09.2018).

[12] NBCC. 2005. National Building Code of Canada. https://www.nrc-cnrc.gc.ca/obj/doc/solutionssolutions/advisory-consultatifs/codes_centre centre_codes/revisions_erratarevisions_errata/HC_ER/1990/NBC1990_1st_revision_errata.pdf. (Erişim Tarihi: 10.09.2018). 
[13] Hong L.L., Hwang W.L. 2000. Empirical formula for fundamental vibration periods of reinforced concrete buildings in Taiwan. Earthquake Engineering and Structural Dynamics, 29 (3): 327-337.

[14] Goel, R.K., Chopra A.K. 1997. Period Formulas for Moment-Resisting Frame Buildings. Journal of Structural Engineering, 123 (11): 1454-1461.

[15] EC8. 2004. Design of structures for earthquake resistance in Part 1: General rules, seismic actions and rules for buildings. https://eurocodes.jrc.ec.europa.eu/doc/WS_335/report/EC8_Seismic_Design_of_BuildingsWorked_examples.pdf. (Erişim Tarihi: 10.09.2018).

[16] Leissa A.W. 2005. The historical bases of the Rayleigh and Ritz methods. Journal of Sound and Vibration, 28 (4): 961-978.

[17] ICPSRDB. 2007. Iranian Code of Practice for Seismic Resistant Design of Buildings. http://iisee.kenken.go.jp/worldlist/26_Iran/Iran\%20National\%20Seismic\%20Code_2007_3rd\%2 OVersion_English.pdf. (Erişim Tarihi: 10.09.2018).

[18] EAK. 2000. Greek code for Seismic Resistant Structures in Organization for Earthquake Resistant Planning and Protection, Ministry of Environment Planning and Public Works, Greece http://iisee.kenken.go.jp/worldlist/21_Greece/21_Greece_Overall.pdf. (Erişim Tarihi: 10.09.2018).

[19] SI-413. 2009. Design Provisions for Earthquake Resistance of Structures. https://www.iec.co.il/Suppliers/101862470/Amendment\%20No\%205\%20to\%20SI\%20413.pdf. (Erişim Tarihi: 10.09.2018).

[20] Indian-Code. 2002. Criteria for Earthquake Resistant Design of Structures, in Design of Structures. http://iisee.kenken.go.jp/worldlist/24_India/24_India_Code.pdf. (Erişim Tarihi: 10.09.2018).

[21] Köse M.M, Karslığlu Ö. 2007. Dolgu Duvarların Bina Doğal Modal Periyot ve Mod Şekline Olan Etkileri. Altınc1 Ulusal Deprem Mühendisliği Konferans1, pp. 261-270, 16-20 Ekim, İstanbul. 